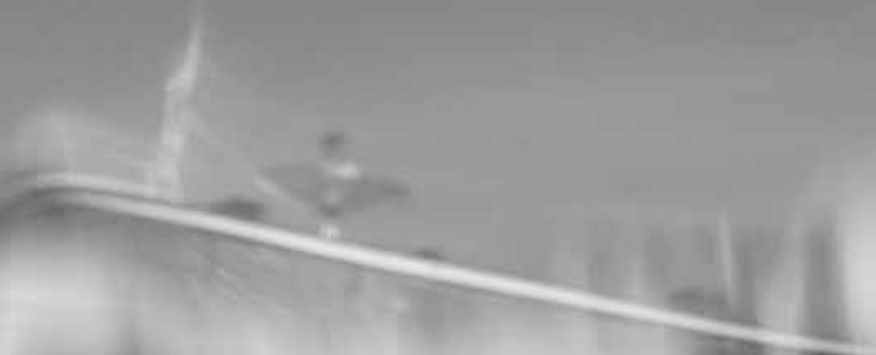




\section{As ciências cognitivas e a pesquisa na criação artística e a estética*}

palavras-chave: ciências cognitivas; pesquisa e arte; teorias da arte e da estética.

keywords: cognitive science; research and art; theories of art and aesthetics.
Este trabalho comenta, num primeiro momento, a história das ciências cognitivas, partindo da cibernética, passando pelo que chamaremos de "cognitivismo", e, depois, pelo que denominaremos "conexionismo", e, chegando, enfim, ao momento atual, que é marcado pela multiplicidade das direções de pesquisa, em que se delineia uma forte tendência crítica aos paradigmas anteriores. Num segundo momento, discute-se a influência das ciências cognitivas sobre as teorias da arte e da estética.

This work comments at first, the history of cognitive sciences from cybernetics to, first, the so called "cognitivism"; secondly, to what we might call "connectionism"; and, finally, to the present day, which is marked by a multiplicity of research directions in which a strong tendency to review the previous paradigms is outlined. In a second moment, the text aims to discuss the influence of cognitive sciences on the theories of art and aesthetics. 
Vimos constituir-se no século passado, a partir dos anos 1950, uma federação de pesquisadores provenientes de horizontes bastante diversos, agrupando especialistas da cibernética, matemáticos, físicos, biólogos, especialistas da teoria dos sistemas e jogos, da informática, antropólogos, psicólogos, neurologistas, linguistas e filósofos. Esses pesquisadores compartilhavam o projeto comum de tratar o espírito e o pensamento como objeto "natural", de origem não transcendental, que funciona segundo processos identificáveis, tal como outros fenômenos da natureza, contrariamente à tradição cartesiana, que separa espírito e matéria. Essas ideias resultariam na possibilidade de "descrever, explicar e, se necessário, simular, e mesmo ampliar, as principais tendências e capacidades do espírito humano - linguagem, raciocínio, percepção, coordenação motora, planejamento, decisão, emoção, consciência, cultura”. Daí os termos de "ciências da cognição", "ciências cognitivas", ou "ciências e tecnologias da cognição", para sublinhar seu caráter técnico, atribuídos a essa federação de disciplinas.

As ciências cognitivas não formam uma federação coerente de disciplinas, fundada sobre um paradigma dominante. Sua história é atravessada por correntes diferentes, cujas divergências, convergências e intersecções são múltiplas. Mas nota-se uma certa progressão em seu desenvolvimento histórico. Distinguimos uma primeira etapa, dita, "cibernética”, em que se pensa que a cognição seria formalizável por meio de operações de lógica matemática: pensar seria calcular, e o substrato biológico não seria necessário para o cálculo. A segunda etapa é a do "cognitivismo", para quem a cognição seria uma computação física de símbolos produzidos por nosso espírito, isto é: estados mentais representando aquilo que substituem. $\mathrm{O}$ computador torna-se, então, o modelo do funcionamento do cérebro e do espírito. A terceira etapa é a do "conexionismo" que, em vez de se fundar sobre a noção de informação, visa ao modo como os sistemas vivos mantêm e reorganizam o equilíbrio interno de seus constituintes, e evoluem estruturalmente, mantendo-se em sua identidade. É um retorno à biologia e à neurologia, um abandono dos símbolos e da computação. A quarta etapa, cronologicamente, a última, e ainda bastante vaga, é caracterizada pela multiplicidade das direções de pesquisa entre as quais delineia-se uma forte tendência que critica os paradigmas anteriores: a cognição dependeria não de representações mentais preexistentes, mas de experiências diversas que as capacidades sensório-motoras de nosso corpo, confrontado com o meio com o qual ele interagiria, nos fariam viver. Ela seria uma "ação encarnada”. 
As teorias revolucionárias expressas pelas ciências cognitivas e a rápida expansão das tecnologias da informação e da comunicação chamaram a atenção de certo número de artistas, que tiraram proveito dessa situação para realizar seus projetos. Para tanto, inspiraram-se em diferentes modelos teóricos e em técnicas de programação produzidas pelas ciências cognitivas no transcorrer dessas etapas. Uma ideia dominante e largamente partilhada conduzia a pesquisa: tratava-se de transferir para a máquina (um dispositivo eletrônico ou um computador) certas competências criadoras próprias ao artista e, com esse fim, dissecar e simular os processos mentais da criação. No início, essas competências eram relativamente simples e se inscreviam no prolongamento da automatização das técnicas (fotografia, cinema, vídeo, televisão, no tocante às imagens; gravação magnética, síntese do som, para a música; algoritmização dos processos sintáxicos e gramaticais, para a poesia e para a ficção narrativa). Os artistas faziam uso das capacidades combinatórias e seriais da máquina, o pseudoacaso como introdutor de variedade, de fórmulas geométricas, algébricas, estatísticas e probabilísticas; esses modelamentos correspondiam globalmente ao período cognitivista.

À medida que as ciências da cognição progrediam e novas teorias apareciam, as competências criadoras transferidas à máquina tornavam-se mais complexas e tendiam a se aproximar da cognição humana - ao menos esta era a intenção dos autores. Quando o computador foi dotado de captadores capazes de integrar informações do mundo exterior, especialmente aquelas emitidas pelas pessoas físicas às quais as obras se dirigiam (observadores, espectadores, auditores, leitores), sua autonomia cresceu consideravelmente. Em vez de responder apenas às informações simbólicas especificamente codificadas, introduzidas pelo teclado alfanumérico, o computador se tornava capaz de integrar informações não simbólicas emitidas por gestos, voz, comportamento geral do usuário, e de responder a isso quase que instantaneamente.

$\mathrm{O}$ conexionismo, por sua vez, produziu novas teorias. O uso das redes miméticas propagou-se e a lógica combinatória foi substituída por uma lógica fundada em particularidades próprias aos sistemas vivos: a autonomia e suas diferentes declinações. As pesquisas orientaram-se, então, para um novo objetivo: a vida como processo capaz de se auto-organizar e de se adaptar a seu ambiente. Mas, simular a vida era também simular 
o comportamento dos seres vivos, especialmente suas emoções, o papel que estas têm nos processos de criação e recepção das obras artísticas, e, em consequência, era tentar revelar os processos mentais subjacentes aos afetos, inspirando-se em experimentações e teorias propostas pelas neurociências e pela psicologia cognitiva. Obras foram concebidas e realizadas nesse sentido ao longo desses últimos anos, inaugurando formas de expressão inéditas.

Para concluir esta primeira parte, eu diria que a influência das ciências cognitivas sobre a criação - ao menos sobre uma parte bastante reduzida da criação contemporânea - traduziu-se em uma transformação profunda das propriedades funcionais e estruturais das obras, que tendem a se autonomizar e a reproduzir certas competências específicas ao próprio artista. Nessa lógica, o artista já não procura produzir artefatos que se fixem para sempre em sua identidade, mas externar suas competências criadoras em um dispositivo técnico evolutivo em interação com seu meio. Essa dinâmica de externação encontra-se, aliás, em muitas outras atividades humanas contemporâneas e se inscreve na evolução do instrumento durante a filogenia. Todo um povo de criaturas virtuais, de atores inteligentes, dotados de emoções e do senso de decisão, está se alastrando à nossa volta através das redes de comunicação, dos jogos e de grande quantidade de dispositivos variados, sem que nos apercebamos claramente. Por mais raras que sejam, essas novas formas de expressão artística inspiradas pelas ciências cognitivas permanecem muito significativas dessa evolução: ao mesmo tempo que a anunciam, também contribuem para ela.

As ciências cognitivas e a estética

A influência das ciências cognitivas exerceu-se também sobre as teorias da arte e a estética. Apresentei uma síntese panorâmica de como essas ciências tinham contribuído para a reflexão sobre a arte em um livro publicado na primavera deste ano, La Nature de l'Art. Ce que les sciences cognitives nous révèlent sur le plaisir esthétique [A natureza da Arte. O que as ciências cognitivas nos revelam sobre o prazer estético], pela Hermann. Os teóricos que se alimentaram desses novos conhecimentos tiveram como objetivo tratar a arte como um objeto "natural", não transcendental e objetivamente conhecível. Em suma, tratava-se de naturalizar a estética. Não me é possível fazer um resumo fiel dessa obra em tão pouco tempo, e me limitarei a recensear de modo muito sucinto suas ideias e os fatos 
ARS mais importantes que põem em dúvida algumas verdades afirmadas pelas teorias da arte e a estética tradicionais.

n 20 Depois de uma apresentação resumida das ciências cognitivas e de sua história, mostrei como a experiência estética e o prazer ligado a ela não são um produto da cultura humana independente de qualquer enraizamento biológico, mas põem em jogo processos cognitivos distintos, selecionados pela evolução, de importância vital para o indivíduo e para a espécie. Dirigimos, todos, naturalmente, ou seja, biologicamente, uma atenção ao mundo, sustentada e permanente, que nos deu a capacidade de nos situarmos neste mundo e de nele agir para nele sobreviver. Um aspecto dessa atenção é a atenção estética: ela se exerce quando há um interesse dirigido, nesse caso, ao que consideramos "belo", seja um objeto natural ou um artefato. É característica de condutas específicas atentas à imensa diversidade das formas que se desenvolvem no entorno. É essencialmente morfotrópica. Para cada indivíduo, reconhecer essas formas como gestalts, dar-lhes um sentido, integrá-las em sua ação, sua história, é uma questão de primeira necessidade. A atenção estética, quando é satisfeita, possui a singularidade de gerar um prazer tingido de emoção por um estímulo do cérebro límbico. Mas não existe nenhuma estrutura neural que lhe seja afetada. A chegada desse prazer, leve ou intenso, dependendo das circunstâncias, age como uma recompensa. E o inverso também ocorre, pois podemos não apreciar certas formas. Geralmente, a atenção morfotrópica investe-se numa pragmática. Serve para alguma coisa e muitas vezes desencadeia uma ação. Mas, na busca do prazer que a recompensa, a atenção estética procura se autoentreter, encontra em si mesma sua finalidade.

Desse ciclo "atenção-prazer-atenção-prazer..." surge o sentimento estético: uma emoção reprocessada pelas áreas corticais do encéfalo e reforçada no nível das representações (ideias, discursos, juízos). Daí a necessidade de compreender o papel das emoções, tão importante na arte. A neurofisiologia contribuiu muito para essa compreensão. Os afetos já não são considerados estados psíquicos inapreensíveis e sem relação com a cognição; muito pelo contrário, são necessários para o raciocínio e para a tomada de decisão. A cesura emoção-razão não é fundada - o que põe fim a uma outra ilusão. Mas a extrema complexidade da função das emoções e dos estados afetivos provocados por um artefato artístico ainda é uma das questões mais difíceis que os pesquisadores têm para resolver. As ciências cognitivas também mostraram que as emoções desempenham um papel 
necessário na comunicação interindividual pois, como manifestações visíEDMOND COUCHOT veis e públicas do corpo, elas nos permitem aceder às emoções dos outros, reconhecê-las e, eventualmente, compartilhá-las. Assim, a arte enriquece consideravelmente nosso universo sensorial e emocional.

À certeza de que a criação artística fosse em essência demiúrgica e permanecesse inacessível ao conhecimento, as ciências cognitivas respondem que ela é o resultado de condutas estéticas cuja visada seria principalmente operatória e se realizaria apropriando-se de formas preexistentes, remodelando-as ou criando novas, para expô-las ao outro com o fim de desencadear prazer e sentimento estéticos. As neurociências determinaram, com base em observações numerosas, e já faz bastante tempo, que certos artistas às vezes têm disposições perceptivas e cognitivas fora do comum, disposições que favorecem o fazer artístico, mas não garantem, em absoluto, que os artefatos criados por aqueles que as possuam sejam obras de arte.

A questão da criação artística suscitou abordagens diferentes da parte dos pesquisadores. Avançam-se várias hipóteses a respeito da maneira como se organizariam os processos heurísticos mentais que conduzem ao surgimento de ideias novas, de invenções ou de descobertas na esfera científica, ou à criação de artefatos com uma visada estética. O que se chama intuição ou inspiração, que tradicionalmente se pensava furtar-se a toda interpretação naturalista, desempenharia aí um papel decisivo. Ligado à história singular e imprevisível de cada um, o conjunto desses processos escaparia a toda lei e regra ou a todo princípio universal determinista. Uma seção, aqui, é dedicada à criação artificial, e lá se encontram as teorias expostas na primeira parte de minha apresentação (a externação dos processos de criação em artefatos técnicos).

Nos capítulos seguintes, recorro a uma noção psicoestética antiga, a empatia, reatualizada pela descoberta recente de certos neurônios, que têm um papel crucial na comunicação intersubjetiva entre os receptores das obras e as obras, bem como entre os receptores e os autores das obras. Desprovida de sua aura romântica, criticada pelos estetas tradicionais, a empatia - faculdade que compartilhamos com certas espécies animais dotaria o destinatário da obra (o amador de arte) com a faculdade de estabelecer uma ressonância sensório-motora e emocional, acompanhada de uma conscientização subjetiva de outrem, com as representações contidas nos artefatos (personagens, formas figurativas ou abstratas, traços físicos diversos, remetendo aos gestos do autor da obra). Ela o dotaria, ademais, 
ARS da faculdade de entrar em ressonância temporal, imediata ou diferida, ano 10 segundo a natureza autográfica ou alográfica das obras, com o autor dos n 20 artefatos, permitindo-lhe, por meio disso, adquirir um conhecimento de seus estados de consciência, de suas emoções, de suas intenções, sem se confundir com ele. O destinatário estabeleceria, assim, uma comunicação intersubjetiva (direta ou indireta) com o autor, encontraria a singularidade de sua vivência e de sua inscrição no tempo e compartilharia com ele o mesmo instante presente próprio ao ato de criação, no seio de uma mesma matriz intersubjetiva. A recepção de uma obra de arte não consiste em uma simples transferência de informação entre a obra e o destinatário; tampouco entre o autor e o destinatário da obra. Ela põe em ação o conjunto do aparelho psíquico e somático do destinatário da obra. Daí se pressupõe que a dimensão estética de uma obra de arte não pode ser contida numa propriedade intrínseca, nem na intenção do autor ou do destinatário. Ela é essencialmente relacional e essa relação instaura-se com base numa ressonância temporal. Experimentamos, no entanto, uma sensibilidade particular, adquirida durante a filogenia (simetria, ritmos sonoros etc.), para com certo número de formas detectáveis nas obras de arte e suscetíveis de provocar uma reação estética elementar da parte do sistema cognitivo. A espécie humana foi sensibilizada a formas subculturais e subssimbólicas que encontramos em todas as culturas, mas são raras e sempre encerradas em formas provenientes das culturas epigenéticas.

Se a parte da filogenia e da herança genética é importante no funcionamento do cérebro e de suas articulações somáticas, sua enorme plasticidade, suas capacidades de adaptação, de memorização e de invenção contrabalançam amplamente as limitações naturais que a modelaram. A universalidade dos processos cognitivos e biológicos implicados na criação e recepção artísticas não impõe obstáculo à diversificação das obras produzidas por esses processos. Essa diversificação convida a infinitas e livres trocas de experiência e de interpretação.

Em uma última parte, reconsiderei as condutas estéticas sob o ângulo evolucionista e mostrei que a espécie humana não é a única a desenvolver condutas desse tipo. À ilusão de que a espécie humana é a única que possui um senso estético que a situaria acima das outras espécies, a etologia cognitiva responde que certos animais também possuem comportamentos de grande riqueza que podem ser interpretados como estéticos. Esses comportamentos (o canto dos pássaros ou das baleias, a dança dos chimpanzés ou dos grous australianos, os ninhos decorados 
dos pássaros-jardineiros) têm certamente funções biológicas atribuídas à sobrevivência e à reprodução da espécie, mas os etologistas constataram As ciências cognitivas que também eram impulsionados pelo prazer mesmo que causavam. Se e a pesquisa na criação os pássaros cantam para os outros e em companhia dos outros, também artística e a estética apreciam seus próprios cantos, que por vezes os inebriam. Os seres vivos possuem uma capacidade que os leva, durante a filogenia, a inventar formas variadas e exuberantes extremamente expressivas, que vão além das funções vitais e reprodutivas. As culturas humanas compartilham com as culturas animais essa mesma dinâmica hipertélica, que se completa na produção de artefatos diversos transmitidos de indivíduo a indivíduo e de geração a geração. Os comportamentos estéticos não são exclusivos à espécie humana.

No entanto, esse transbordamento das funções básicas pode conduzir a certa desestabilização das culturas humanas. Estas então imaginaram diferentes meios para controlá-lo, subordinando a produção dos artefatos estéticos a funções culturais e sociais consideradas superiores - sexuais, simbólicas, religiosas, clânicas, políticas, lúdicas, econômicas, entre outras. A originalidade da cultura ocidental foi autonomizar essa produção, deslocando-a, porém, sob outro controle, o da esfera da Arte e de suas instituições. Nossa cultura empenha-se em definir a arte não tanto no que ela é, mas no que deve ser, ou seja, detentora de uma missão sagrada que confere à nossa espécie um estatuto excepcional entre os organismos vivos. Ela é extremamente injuntiva e normativa. Essa ideologia, que impregna os espíritos com força crescente, contradiz radicalmente a abordagem naturalista da arte.

As ciências cognitivas mostram ainda que a tradicional e sistemática oposição entre racionalidade científica e sensibilidade artística, objetividade científica e subjetividade artística não tem fundamento. A ciência e a arte são duas atividades que apresentam em concomitância diferenças e similitudes. Similitudes, quanto aos processos de criação ou de invenção/ descoberta e quanto à função das emoções nesses processos. Diferenças, quanto à função das emoções e da empatia na recepção das obras de arte e na comunicação dos conhecimentos científicos, e quanto aos efeitos que essas obras e esses conhecimentos exercem sobre cada pessoa e sobre a sociedade. As finalidades da ciência e da arte não são as mesmas.

Por fim, à crença de que os únicos verdadeiros conhecimentos são os que a ciência nos proporciona, fundados em raciocínios lógicos, as ciências cognitivas respondem que a arte é capaz de nos fazer adquirir 
ARS conhecimentos de valor igualmente elevado sobre o mundo e sobre nós ano 10 mesmos. Mas o valor cognitivo desses conhecimentos difere dos que a n 20 ciência proporciona. A arte aguça primeiramente nossa aptidão para criar, penetrar e explorar mundos imaginários, como se tivessem a mesma espessura de ser que os mundos reais, para elaborar hipóteses sobre o sentido desses mundos, antecipar seu futuro, inscrever-se em sua própria temporalidade e jogar com as formas do tempo. Durante a recepção das obras de arte experimentamos emoções fortes e inabituais que ampliam nossa gama de emoções, nossa competência para decifrar as emoções de outrem e compartilhá-las como prazer estético. A arte nos ensina também a educar, controlar e socializar nossas emoções.

Que conclusão tirar, finalmente, dessas duas direções de pesquisa, uma orientada para a reprodução dos processos da criação e sua externação, e outra, para a naturalização da estética, ambas referindo-se aos mesmos conhecimentos, provenientes das ciências e das tecnologias da cognição? Responderei que tal convergência entre as práticas artísticas e as teorias da arte é, de um ponto de vista histórico, um fato sem precedente, que abre um campo totalmente novo para a pesquisa, tanto na prática das artes quanto nos instrumentos conceituais dedicados à arte; e que esse campo mal começou a ser explorado e envolve pesquisadores, artistas e teóricos em um projeto de prazo bastante longo, em que as relações entre a ciência e a arte exigem ser refundadas.

* Este trabalho foi apresentado no Seminário Internacional ARTE_PESQUISA: Inter-Relações, promovido pelo Programa de Pós-Graduação em Artes da UNESP, pelo

Programa de

Pós-Graduação em Artes Visuais da USP e pelo Programa de Pós-Graduação em Artes Visuais da UNICAMP, e realizado entre os dias 9 e 11 de outubro de 2012 no Instituto de Artes da UNESP, São Paulo. A conferência foi realizada no dia 09 de outubro de 2012.
Doutor e Professor Titular Emérito, Edmond Couchot dirigiu o departamento de Artes e Tecnologias da Imagem na Universidade Paris 8 durante duas décadas, e continua participando de Pesquisas do Centro Imagens Digitais e Realidade Virtual - INREV. Sua área de ensino e pesquisa são as interações entre a arte e a ciência, principalmente entre as teorias da arte e da estética e as ciências e tecnologias da cognição. Desde 1965, Edmond Couchot compartilha as atividades da Associação Francesa de Cibernética e Sistemas Gerais, e já criou dispositivos eletrônicos interativos que reagem ao som e solicitam a participação do espectador. Há alguns anos, os recursos de "tempo real" permitiram-lhe prolongar essas pesquisas e participar de inúmeras exposições internacionais. Publicou diversos estudos sobre o assunto, entre os quais destaacam-se: Image. De l'optique au numérique (Hermès, Paris, 1988); A tecnologia na arte. Da fotografia à realidade virtual (Universidade Federal do Rio Grande do Sul, 2003); L'Art numérique. Comment la technologie vient au monde de l'art (Flammarion, 2003, em colaboração com Norbert Hillaire); Des images, du temps et des machines, dans les arts et la communication (Éditions Jacqueline Chambon, 2007); e La Nature de l'Art. Ce que les sciences cognitives nous révèlent sur le plaisir esthétique (Hermann, 2012). 